\title{
AGROECOLOGIA E TURISMO: REFLEXÕES E SABERES TRANSDISCIPLINARES PARA O DESENVOLVIMENTO SUSTENTÁVEL
}

\author{
Caroline Ciliane Ceretta ${ }^{1}$ \\ Charlene Brum Del Puerto ${ }^{2}$ \\ Greicy Sofia Maysonnave ${ }^{3}$
}

\begin{abstract}
RESUMO
A agroecologia e o turismo são duas áreas complexas que influenciam e são influenciadas por diferentes áreas do conhecimento, principalmente quando a discussão é cercada por iniciativas em busca da sustentabilidade. Nessa perspectiva, o artigo objetiva analisar o aporte teórico que aproxima a agroecologia do turismo a partir do olhar da transdisciplinaridade que os retroalimenta. Especificamente, busca-se refletir sobre o papel do turismo e da agroecologia enquanto cúmplices transdisciplinares dos diversos saberes para sua prática e contextualizar as perspectivas do desenvolvimento sustentável do turismo, bem como discutir o sentido da agroecologia no âmbito do turismo. $O$ artigo se caracteriza como sendo de caráter qualitativo e exploratório com a coleta de dados bibliográficos para a revisão e reflexão em estudos científicos e documentais. $\mathrm{Na}$ discussão, o entendimento transdisciplinar permite compreender o status quo do movimento do turismo e da agroecologia em busca da sustentabilidade do ambiente vivenciado. Por fim, o artigo mostra que a sustentabilidade poderá ser atingida quando atitudes responsáveis aproximarem as áreas do saber e do fazer, do sentir e do agir.
\end{abstract}

Palavras-chave: Agroecologia, ambiente, sustentabilidade, transdisciplinaridade, turismo.

\section{AGROECOLOGY AND TOURISM: REFLECTIONS AND TRANSDISCIPLINARY KNOWLEDGE FOR SUSTAINABLE DEVELOPMENT}

\begin{abstract}
Agroecology and tourism are two complex areas that influence and are influenced by different areas of knowledge, especially when the discussion is surrounded by initiatives in search of sustainabiliby. In this perspective the article aims to analyze the theoretical basis that approximates the agroecology and tourism, from the look of transdisciplinarity that feeds them. Specifically, it seeks to reflect on the role of

\footnotetext{
${ }^{1}$ Doutora em Extensão Rural (UFSM). Mestre em Turismo (UCS). Bacharel em Turismo (UNISC). Docente do Departamento de Turismo da Universidade Federal de Santa Maria (UFSM). E-mail: carolineceretta@hotmail.com.

2 Mestre em Turismo (UCS). Especialista em Gestão Pública e Desenvolvimento Regional (UFPEL) Especialista em Gestão e Docência no Ensino Superior (UNOESTE). Especialização em Educação e Direitos Humanos (FURG). Bacharel em Turismo (UFPEL). E-mail: charlenedelpuerto@bol.com.br

${ }^{3}$ Doutora em Zootecnia (UFSM). Mestre em Zootecnia (UFSM). Graduada em Zootecnia (UFSM). Graduada em Licenciatura Plena (UFSM). E-mail: greicysm@gmail.com.
} 
tourism and agro-ecology as transdisciplinary of the various disciplinary knowledge to their practice; contextualize the prospects of sustainable tourism development, as well as discussing the meaning of agroecology in the context of tourism. The article is characterized as being of bibliographical character, review and reflection on scientific and documentary studies. In the discussion, the transdisciplinary understanding allows us to understand the status quo of the movement of tourism and agroecology towards sustainability of the environment used. Finally, the article shows that sustainability can be achieved when responsible attitudes approach all areas of learning and doing, feeling and acting.

keywords: Agroecology, environment, sustainability, transdisciplinarity, tourism.

\section{INTRODUÇÃO}

As transformações ocasionadas pela globalização na sociedade causam incertezas e inquietudes sobre seus reais e convincentes efeitos, seja na economia das sociedades consagradas ou emergentes, nos setores produtivos, nos serviços, na natureza, etc., seja no ambiente ecológico, social, político, do conhecimento, cultural ou outro vivenciados. O que importa é que, dentre estes e outros efeitos, o setor turístico enfrentou e ainda enfrenta um processo dinâmico de transformações, de reutilização e usos de seus espaços, de incorporação de pluriatividades, de multifuncionalidades, de novos programas governamentais para o uso responsável da atividade turística e, principalmente, do movimento ecológico.

A agroecologia também passa por transformações, seja de ordem técnicocientífica em função de processos de plantio e manejo da terra ou mesmo pela dimensão de atividades extra-campo que ela ganhou nos últimos anos. Essa expansão do conhecimento agroecológico é explicada por Preiss (2020, p.106) como [...] "um resultado dos processos de vivência e experiência dos agricultores na gestão (muitas vezes coletiva) dos bens comuns e nos caminhos encontrados para produção de alimentos, aliada ao desenvolvimento sustentável".

De amplitude singular, a revolução paradigmática da agroecologia também evidencia mudanças na terra e na sociedade, uma vez que a complexidade dos ecossistemas abrange a agricultura, a sociedade, a política e os recursos culturais e naturais, bem como as diversas inter-relações e reações que a sociedade constrói e elege para sobreviver. Isso acontece porque a agroecologia busca denunciar a insustentabilidade da monocultura e defender uma economia ecológica, branda e voltada à precaução dos atos insustentáveis, apostando no diálogo de saberes e na transdisciplinaridade dos conhecimentos, de maneira que se consiga superar 0 reducionismo e a fragmentação social nos mais diversos aspectos (PAIVA, 2019). Nesse sentido, ao conectar-se com o fenômeno turístico, o movimento da agroecologia reforça o sentido da transformação social, cujos fundamentos de sua essência ultrapassam as práticas agrícolas e comprometem-se com a transição discursiva entre a ciência, a sociedade e o turismo sustentável.

Desde a década de 1980, o turismo e outras atividades tradicionais, como a agricultura, viram-se diante da necessidade de mudar o crescimento desenfreado de suas produções até então voltadas para a essência economicista e produtivista, para um processo de desenvolvimento mais responsável e menos inconveniente para a riqueza do ecossistema (BENI, 2006). Silva et al. (2017, p. 434) explicam que "frente às novas atribuições da agricultura, despontam atividades não agrícolas, que buscam não apenas dinamizar a economia do espaço rural, mas também atender às necessidades emergentes de uma sociedade mais consciente", tal como vem se 
mostrando aquelas voltadas para valorizar as multifuncionalidades dos territórios e a pluralidade de homens e mulheres rurais.

A proposta de uma atividade menos "massiva", planejada, ecologicamente correta e sustentável fez com que o setor turístico se reorganizasse em seus discursos globais, preconizando o uso racional dos recursos naturais e culturais, a dita essência da matéria-prima do turismo (BENI, 2003). Neste aspecto, as áreas de agroecologia e de turismo defendem o uso racional destes recursos, de maneira que a interconexão de práticas sustentáveis, saberes, a ciência e o próprio engajamento social se traduzam em atitudes responsáveis e inteligentes entre atos e narrativas em nome da salvaguarda do ecossistema.

Por ser um produto capaz de agregar valor à cadeia produtiva estabelecida, o turismo, em sua plenitude de produção sustentável, é um facilitador de práticas preservacionistas e amenas dos usos dos recursos naturais e culturais dos destinos turísticos, mesmo que sua prática produza índices significativos de geração de novos empregos e agregações socioeconômicas, motivo pelo qual se expande na esfera global sem precedentes, obviamente, trazendo consigo, preocupações com os usos e discursos incentivadores de sua prática.

Nos anos de 1990, a emergência de um novo turismo, plural e com responsabilidade ambiental nas suas ações, inclinou os discursos para uma atividade socioeconômica que pudesse voltar-se para uma economia de valor com incentivos às trocas e iniciativas em proximidade, o que trouxe elementos inovadores na sua cadeia produtiva. Há que se considerar o papel do turismo para a emergência ambiental de salvaguarda dos recursos existentes nos territórios, como uma estratégia de agregar valor às economias locais, principalmente aos elementos culturais e históricos que tornam o ambiente único e, portanto, com potencial de atratividade (PECQUEUR, 2005).

Nesse sentido, verificam-se as possibilidades de sustentabilidade dos territórios potencialmente atrativos, buscando compreender, na relação entre turismo e a agroecologia, a maneira como tais áreas do saber se entrelaçam e se complementam. Cabe pensar, de que maneira ocorre tal entrelaçamento, uma vez que ao se apropriarem de seus saberes, efetivamente minimizariam o uso irresponsável do ambiente, seja ele físico, social, cultural, político ou qualquer outro existente no ecossistema.

De natureza multiplicadora, complexa, e não mais exclusivamente disciplinar, a atividade turística é um reflexo da evolução da sociedade capitalista, evidenciando múltiplas oportunidades e paradigmas em suas diversas inserções nos destinos consagrados ou não. Nesse sentido, é possível conceber o turismo não apenas com o intuito de utilizar os recursos naturais e culturais para a ativação do consumo no ambiente, mas também com o propósito de reunir diferentes áreas do saber com o propósito de que as iniciativas e interferências nos lugares não sejam causadoras de prejuízos e destruição do ecossistema.

Nesta concepção, Sonaglio e Lapolli (2003) evidenciam a transdisciplinaridade como sendo reconhecida por estar regida por lógicas distintas, pelo reconhecimento de diferentes níveis de realidade e pela zona de não resistência, considerando o raciocínio complexo, ampliando as possibilidades de melhor realizar os projetos ecoturísticos e sendo capaz de auxiliar na conduta dentro do domínio das experiências. Há que se pensar num campo não exclusivamente disciplinar, de um ou outro saber estar como responsável pela sustentabilidade ambiental, mas sim de uma nova esfera transdisciplinar, incorporando conhecimentos e concebendo o enfoque agroecológico que presencia as ações no território, na sociedade, no turismo ou em outro ambiente que se estabeleça. 
Nesse sentido, o estudo tem como objetivo principal analisar o aporte teórico que aproxima a agroecologia e o turismo a partir do olhar da transdisciplinaridade que os retroalimenta nas tarefas da sustentabilidade. Especificamente, o estudo busca refletir sobre o papel do turismo e da agroecologia enquanto cúmplices transdisciplinares dos diversos saberes para sua prática e contextualizar as perspectivas do desenvolvimento sustentável do turismo, bem como discutir o sentido da agroecologia no âmbito do turismo.

Metodologicamente, o estudo caracteriza-se como sendo um artigo de revisão bibliográfica, uma vez que busca analisar informações já publicadas a respeito da temática (LONGARAY; BEUREN, 2003). O trabalho também apresenta o caráter exploratório qualitativo no que tange às temáticas abordadas. Para tanto, a discussão vale-se da análise e interpretação das narrativas de conteúdo, que segundo Richardson (1999), produz melhor compreensão do discurso, aprofunda características cognitivas, ideológicas e gramaticais, extraindo, assim, os momentos relevantes para o referencial que se quer refletir.

Entretanto, as reflexões que se descortinam são compostas por dois eixos temáticos: um, conectando a agroecologia e o turismo na esfera transdisciplinar; e o outro apresentando as perspectivas territoriais sustentáveis do turismo no processo de desenvolvimento que se entende. Por fim, apresenta-se o entendimento de que a partir da concepção transdisciplinar é possível compreender o status quo do movimento do turismo e da agroecologia para a sustentabilidade do ambiente.

\section{AGROECOLOGIA E TURISMO: CUMPLICIDADE TRANSDISCIPLINAR}

Ao pensar a cumplicidade transdisciplinar, logo se estabelece o desafio de conceber a agroecologia e o turismo no âmbito do saber. A relação entre estas áreas possui entrelaçamentos múltiplos, visto que envolvem distintas possibilidades de compreensão. O turismo, por exemplo, enquanto uma área social, abrange trocas, informações e culturas, entre outros aspectos que sinalizam para a complexidade da atividade. Moesch (2002, p. 9) aponta que:

O turismo é uma combinação complexa de interrelacionamento entre produção e serviços, em cuja composição integram-se uma prática social com base cultural, com herança histórica, ao meio ambiente diverso, cartografia natural, relações sociais de hospitalidade e troca de informações interculturais. O somatório dessa dinâmica sociocultural gera um fenômeno, recheado de objetividade/subjetividade [...].

A atividade turística começa a se aprofundar como campo de estudo científico a partir da década de 1970 e, desde então, ela tem sido repensada, reavaliada e ressignificada, tanto nas suas ações como no ambiente em que ocorre.

O campo do turismo, para a pesquisa, é vasto e ainda possui muitas lacunas a serem preenchidas, mas pensar a atividade pelo viés subjetivo, pela experiência, pela ressignificação dos locais, é considerar que o turismo é mais amplo do que o simples fato de organizar um roteiro. Assim, acredita-se que pensar o turismo, através das vivências, de suas valorações e dos sujeitos envolvidos é algo que aumenta as possibilidades teórico/conceituais no sentido de compreender e explicar o que significa esta atividade para a sociedade (DEL PUERTO, 2016, p. 29). 
Nesse sentido, o repensar das atitudes e ações da área de turismo se apropria diretamente do saber da agroecologia para, em uma visão holística e sistêmica, melhor reaproveitar os espaços turísticos com atividades que não degradem o meio ambiente e que proponham aos visitantes práticas sustentáveis. É neste sentido que ambas as áreas em constante conexão podem dialogar e contribuir mutuamente para o uso racional e inteligente dos destinos turísticos em construção ou já consolidados. Neste sentido, propõe-se: usar indicadores de monitoramento de impacto ambiental e sanitário; verificar a capacidade do lugar para o uso e consumo turístico do atrativo; estabelecer condições de acesso e trafegabilidade nas comunidades próximas aos atrativos; primar pela segurança alimentar e patrimonial ou mesmo controlar os níveis de poluição sonora, visual e do ar. Estes são alguns dos fatores necessários que devem estar presentes nos planos diretores de turismo estabelecidos desde as governanças municipais.

A agroecologia não trata apenas de uma prática agrícola, mas se destaca pelo diálogo com saberes científicos e não científicos, visto que é inter e transdisciplinar em sua essência. Entende-se assim que a agroecologia se conecta à ecologia, ciências agrárias e florestais, ciências sociais, geografia, história, economia e educação popular, entre outras áreas de estudo (CAPORAL, 2009). Isso evidencia sua complexidade, tal como Preiss (2020) vem explicando, pois para ele a agroecologia torna-se complexa, diferentemente da forma agrícola convencional, a qual possibilita a reprodução mecanizada e em larga escala. Para o autor, a "[...] expansão da agroecologia passa necessariamente por fomentar o desenvolvimento local de conhecimentos" (PREISS, 2020, p.106).

No Brasil, a agroecologia como campo de produção científica ganhou notoriedade a partir dos anos 1970, embora sua origem seja tão antiga quando a da agricultura, antes mesmo do período da modernização, praticada tanto por imigrantes europeus com um sistema de gestão natural de uso do solo quanto por nativos, descendentes de índios, cujo saber e o fazer estavam baseados nas leis da natureza (BRANDENBURG, 2002). A aplicação de seus princípios na agricultura, na organização social e no estabelecimento de novas formas de relação entre sociedade e natureza também remontam àquela época. Para Brandenburg (2002), a agricultura ecológica no Brasil surgiu no contexto de uma política agrária excludente, motivada por organizações políticas engajadas e com o intuito de conceber uma sociedade democrática e capaz de transformação social. Foi o resultado de um contramovimento da política de modernização agrícola, de modo que seu caráter excludente colocou em risco o pequeno agricultor, o familiar, sem acesso a subsídios governamentais para o crédito agrícola. $\mathrm{E}$, desde então, o movimento dos jovens agricultores dos anos de 1970 passou a dinamizar a agricultura alternativa como forma de obter notoriedade, reconhecimento da sociedade e a institucionalização do padrão ecológico de produção (BRANDENBURG, 2002).

Nesse sentido, Costa Gomes e Borba (2004) consideram que a agroecologia representa um poderoso instrumento e uma necessidade para a ruptura com a tradição epistemológica nascida no empirismo, no racionalismo e no positivismo. É a representação de um avanço paradigmático para os que estão em busca do novo e das origens, pois incorpora a complexidade, a dúvida, ao mesmo tempo em que se propõe atuar inter e transdisciplinarmente. Sua pauta é a temática e não a disciplina, além de reconhecer os saberes tradicionais e cotidianos como saberes válidos (COSTA GOMES; BORBA, 2004).

Para Guzmán (2002), a agroecologia propõe não só modificar a parcelização disciplinar, mas também a epistemologia da ciência, ao trabalhar mediante distintas disciplinas e "formas de conhecimento" que compõem seu 
pluralismo dual: metodológico e epistemológico, em que a perspectiva sociológica tem um papel central. Para o autor, a agroecologia tem uma natureza social e apoiase na ação coletiva de determinados setores da sociedade civil vinculados ao manejo dos recursos naturais, razão pela qual é também sociológica.

A perspectiva estrutural da agroecologia para Guzmán (2002) permite preparar o terreno para o desenvolvimento de uma agricultura participativa, fazendo emergir, assim, uma dimensão global de busca de melhorias no nível de vida das comunidades rurais envolvidas, definindo este nível ou parâmetro desde elas mesmas. Assim, é possível pensar um desenvolvimento rural desde a agricultura participativa como o conjunto de esquemas de desenvolvimento que partem do reconhecimento, da necessidade e/ou do interesse de trabalhar com as comunidades locais na identificação, no desenho, na implementação e na avaliação dos métodos para o desenvolvimento endógeno adequado para a resolução de problemas. Neste processo, as experiências dos sujeitos locais são fundamentais e servem como base para decisões futuras.

A agroecologia pretende, sobretudo, incorporar ao manejo dos recursos naturais os elementos socioeconômicos e políticos. Para isso, necessita produzir uma ruptura epistemológica que liberte as ciências agropecuárias e florestais das relações de poder que atribuem àqueles que são objeto do poder (os pesquisados), a condição de ignorados, dotando-os, ao mesmo tempo, de um saber ilusório que encobre a realidade dos que ignoram, ocultando o fato do poder e sua brutalidade.

Para Kaufmann, Reiniger e Wizniewsky (2018) a maneira como o ser humano desenvolve a agricultura e estabelece suas preferências ecológicas estabelecerá o manejo dos recursos naturais mais adequados aos princípios da sustentabilidade, o que permitirá maior equilíbrio para o próprio manejo dos ecossistemas e a conservação da biodiversidade, o que, de fato, retrata e orienta para a construção de uma nova realidade, desta vez voltada ao pensamento agroecológico, que impacta e é impactado pelos mais diversos modos de interferência humana, seja para atividades agrícolas, não agrícolas, domésticas ou fora dela.

Para Gliessman (2003), o pensamento agroecológico permite uma análise das entradas e saídas de um agroecossistema, em uma forma parecida a uma "piscina num rio". O agricultor, por exemplo, tem que pensar além de sua parcela para entender o que entra de fora para dentro, mais os impactos do rio, do manejo da parte. Assim, o autor aponta quatro componentes importantes para o estudo da sustentabilidade dos agroecossistemas: o fluxo de energia, os ciclos dos nutrientes, os mecanismos de regulação e o equilíbrio dinâmico do sistema. Nesse aspecto, a sustentabilidade como um conceito emergente e integrante da agroecologia está presente nas ações do ambiente como um todo, sejam culturais, econômicas, sociais, naturais, tradicionais, indígenas ou outras. Da mesma forma, o turismo, enquanto fenômeno socioeconômico de dimensões sistêmicas, é analisado teoricamente por sua estrutura analítica de partes influenciáveis e influenciadas por diversas áreas do conhecimento, de maneira que revelam sua natureza compósita e transdisciplinar, num complexo de diferentes áreas, fenômenos e fatores globais de retração e movimentação social que impactam e são impactados entre si (BENI, 2003).

Cabe, portanto, compreender que a complexidade que aproxima a agroecologia, o turismo e a transdisciplinaridade estão justamente na capacidade destas áreas de influenciar e serem influenciadas direta e indiretamente por diversas áreas, ações e fenômenos, dotados de particularidades e sentidos que sempre se cruzam para gerar um efeito ou impacto. É nesse cruzar de fatos que a transdisciplinaridade revela seu papel de conectar os processos em curso para 
equilibrar os fatos e as iniciativas pensadas. $O$ entrelaçamento do turismo com a agroecologia visa a interação do ser humano com a natureza, saindo da ideia de um turismo com foco apenas no lucro. Em um ambiente agroecológico, é impossível não levar em conta as relações do sujeito com a terra e com a ideia autossustentável. A proposta turística com a agroecologia busca um viés de se pensar holisticamente o lugar visitado, considerando todo o processo agroecológico e também do fazer turístico; consiste, então, em uma proposta transdisciplinar.

Desde o conhecimento público, em sete de março de 1986, houve um novo momento de reflexão da sociedade, em que o termo "transdisciplinaridade" se explicitava a partir do Colóquio organizado pela Declaração de Veneza proposta pela UNESCO, conforme o Centro de Educação Transdisciplinar (CETRANS, 2019) apud Sonaglio e Lapolli (2003). Neste momento, urgia a necessidade de troca dinâmica entre as ciências exatas, as ciências humanas, a arte e a tradição, que, no novo enfoque transdisciplinar, proporia um estudo conjunto da natureza e do imaginário, do universo e do ser humano, aproximando mais o ser humano do real e permitindo enfrentar melhor os diferentes desafios da época.

Para o Centro de Estudos Transdisciplinares (2019),

A transdisciplinaridade é uma teoria do conhecimento, é uma compreensão de processos, é um diálogo entre as diferentes áreas do saber e uma aventura do espírito. A transdisciplinaridade é uma nova atitude, é a assimilação de uma cultura, é uma arte, no sentido da capacidade de articular a multirreferencialidade e a multidimensionalidade do ser humano e do mundo (CETRANS, 2019, p.1).

De fato, a transdisciplinaridade implica numa postura sensível, intelectual e transcendental perante si mesmo e ao mundo, além de aprender a decodificar as informações provenientes dos diferentes níveis que compõem o ser humano e como eles repercutem na sociedade. Ela transforma o olhar sobre o individual, o cultural e o social, remetendo à reflexão respeitosa e aberta sobre as culturas do presente e do passado, buscando contribuir para a sustentabilidade. Seus três pilares metodológicos são a complexidade, subjetividade e os níveis de realidade (CETRANS, 2019). Ela emerge como um diálogo constante entre a parte e o todo e os três pilares da transdisciplinaridade permitem que ela também encontre seu lugar na pesquisa e na aplicação.

O olhar transdisciplinar busca encontrar os princípios convergentes entre todas as culturas para que uma visão e um diálogo transcultural, transnacional e transreligioso possam emergir, o que leva também à relativização radical de cada olhar, mas sem cair no relativismo, uma vez que a transdisciplinaridade nos permite encontrar o mundo comum o/a concordiamundis e o terceiro incluído entre cada par de contraditórios (CETRANS, 2019, p.1).

Em sua essência, a transdisciplinaridade é o respeito pelas diferenças, é solidária na satisfação das necessidades fundamentais e na busca de uma convivência harmoniosa com a natureza, podendo transitar sem resistência por diversos níveis de realidade: afetivo, conceitual, estratégico, conceptivo, cognitivo e efetivo. Nesse sentido, há o reconhecimento do turismo como atividade socioeconômica, cujo deslocamento de pessoas impacta o ambiente e é impactado por ele numa lógica sistêmica e híbrida (BENI, 2003). O enfoque da 
transdisciplinaridade também vem sendo discutido à medida que os estudos científicos avançam e demonstram a importância do fenômeno turístico como área desta natureza.

Embora existam obstáculos e dúvidas na área do saber turístico, o mesmo já apresenta a consolidação de um modelo multidisciplinar ou interdisciplinar adotado por muitos estudiosos e mais facilmente adaptado às estruturas institucionais existentes (REJOWSKI, 1996). Ainda está em aberto e relativizado o não reconhecimento do campo do turismo como área que transcende a esfera disciplinar. O turismo é um fenômeno capaz de envolver outras áreas das ciências no sentido de emergir uma nova disciplina.

Para Rejowski (1996), a discussão da questão da disciplinaridade na área de turismo perpassa por três conceitos, isto é, da pluriatividade ou multidisciplinaridade, da interdisciplinaridade e da transdisciplinaridade, cada qual com suas discussões e buscas científicas para justificar a base do turismo como área acadêmica.

No caso da transdisciplinaridade, Rejowski (1996) considera a necessidade de envolvimento de um grupo de especialistas do mais alto nível, trabalhando em conjunto com elevado espírito de equipe interdisciplinar, sem impor suas próprias ideias, o que comporia um estado ideal para o desenvolvimento de estudos e pesquisas numa área interdisciplinar como é o turismo.

$\mathrm{Na}$ Carta da transdisciplinaridade, produzida no I Congresso Mundial de Transdisciplinaridade em 1994, realizado em Arrábida, Portugal, com a colaboração do Centre International de Recherches et d'Études transdisciplinaires (CIRET) e apoio da UNESCO, tem-se uma definição do conceito transdisciplinar, a qual consta no artigo 3: "[...] A Transdisciplinaridade não procura a dominação de várias disciplinas, mas a abertura de todas as disciplinas ao que as atravessa e as ultrapassa". No artigo $5^{\circ}$ da Carta da transdisciplinaridade consta que a visão transdisciplinar é resolutamente aberta na medida que ultrapassa o campo das ciências exatas, devido a seu diálogo e sua reconciliação, não apenas com as ciências humanas, mas também com a arte, a literatura, a poesia e a experiência interior. Ao referir-se à interdisciplinaridade e à multidisciplinaridade, no artigo 60, mostra que a transdisciplinaridade é multireferencial e multidimensional, não excluindo a existência de um horizonte trans histórico (CARTA DA TRANSDISCIPLINARIDADE, 1994).

A carta da transdisciplinaridade cita que o rigor, a abertura e a tolerância são as características fundamentais da atitude e da visão transdisciplinar. O rigor na argumentação que leva em conta todos os dados é a melhor barreira em relação aos possíveis desvios. A abertura comporta a aceitação do desconhecido, do inesperado e do imprevisível e a tolerância no reconhecimento do direito às ideias e verdades contrárias às nossas (CARTA DA TRANSDISCIPLINARIDADE, 1994).

Nessa linha, o setor turístico, como apontado pela Organização Mundial do Turismo (OMT, 2013), promoveu o recorde de 1 bilhão de viajantes, com uma alta de $4 \%$ em relação ao ano de 2012, apesar de todo o contexto global de instabilidade econômica. A longo prazo, a OMT prevê uma alta na circulação internacional chegando a 3,8\% anual em média, entre os anos de 2010 e 2020 , e atingindo a marca de 1,8 bilhão até 2030. Atualmente, para as Américas, o crescimento em 2020 chegaria a 282 milhões de viagens internacionais, antes da avalanche pandêmica global a qual ainda se experimenta mundialmente. Há poucos anos, os jogos da Copa do Mundo e das Olimpíadas realizadas no Brasil superaram as expectativas do fluxo de visitantes, pois em 2014 (Copa do Mundo) o Brasil chegou a receber 6,4 milhões de viajantes de outros países. Já em 2016, no ano das Olimpíadas, foram registradas 6,6 milhões de pessoas desembarcando no país, superando o fluxo da 
Copa (TORRESAN, 2018). Em termos de capital, o Ministério do Turismo (2019) informou que no período de janeiro a dezembro de 2018 os turistas internacionais injetaram US $\$ 5,92$ bilhões na economia brasileira, frente aos US $\$ 5,81$ bilhões registrados no mesmo período de 2017 (BRASIL, 2019).

Como se percebe, o aparato da dinâmica da atividade turística está na busca da sustentabilidade das ações e reações, que por ora transcende o âmbito disciplinar e passa a ser evocado por toda a sociedade, adotando-se significativamente uma estrutura que indique um conjunto de diretrizes baseadas nas dimensões de sustentabilidade (ambiental, social, econômica, cultural, política, institucional ou outra) aplicadas a partir das atividades turísticas e seus equipamentos de apoio, tais como transporte, alojamento, alimentação e demais serviços.

Portanto, a cumplicidade da agroecologia e o turismo estão no saber transdisciplinar que os integra, permitindo que se evolua na concepção teórica, científica e prática, uma vez que o rigor, a abertura e a tolerância também são as características fundamentais de quem atua com a atividade turística ou na agronomia e, obviamente, com o entendimento da agroecologia em todos os âmbitos das atividades a serem realizadas.

\section{DESENVOLVIMENTO E PERSPECTIVAS TERRITORIAIS SUSTENTÁVEIS DO TURISMO}

O desenvolvimento sustentável, com seus complementares e diferentes conceitos, apresenta, em si, uma essência inegável e é, conforme a organização de conservação global (WWF, 2014), capaz de suprir as necessidades da geração atual sem comprometer a capacidade de atender às necessidades das futuras gerações. Os Objetivos do Desenvolvimento Sustentável (ODS) da Agenda 2030, por exemplo, vão ao encontro do que se propõe a agroecologia no que diz respeito à segurança alimentar, às mudanças sociais, à viabilidade econômica da atividade e manutenção do meio ambiente. É o desenvolvimento que não esgota os recursos para o futuro, como definiu a Comissão Mundial sobre Meio Ambiente e Desenvolvimento, criada pelas Nações Unidas para discutir e propor meios de harmonizar os objetivos de desenvolvimento econômico e da conservação ambiental. A construção dos espaços agroecológicos permite diferentes dinamizações sociais que podem conduzir à pluriatividade como, por exemplo, o turismo aqui concebido.

No Brasil, a retomada do turismo como uma atividade comprometida com o desenvolvimento sustentável deu início a um novo formato, no qual os efeitos globais da prática de um turismo massivo, desordenado e sem limites, que marcaram os anos de 1950 a 1980 no país, foram superados com o incentivo do governo federal para mudanças em relação ao planejamento e a gestão da atividade (BENI, 2006).

Nos próximos anos, as atividades de turismo deverão estar aliadas à efetivação de práticas sustentáveis harmoniosas com a natureza, integradas e reconhecidas por seus pares públicos e privados. Toda a oferta turística deverá se mobilizar para gerar serviços de qualidade e reconhecer, por exemplo, valores turísticos na cultura, na história, na gastronomia local e no equilíbrio do ecossistema que a salvaguarda.

Ao mesmo tempo em que a globalização leva a um cenário de contínua informação na economia mundial, de aumento das disparidades internacionais e inter-regionais, conduz também a uma maior liberdade de atuação e de ampla abertura econômica. Com isso, o local deverá assumir o protagonismo de sua gestão e as ações sustentáveis marcarão o diferencial dos destinos e produtos, já 
que equipamentos e conforto não são mais os únicos fatores de diferenciação e escolha dos destinos turísticos.

Nesta dimensão global, poderão se destacar os países que conseguirem a articulação de seus sistemas produtivos com alta competitividade em mercados globais e aqueles que conseguirem planejar o potencial turístico, institucionalizando parcerias e alianças público-privadas como poderosos instrumentos para atingir a desejável articulação em redes de cooperação produtiva, como forma de consolidar o desenvolvimento sustentável (BENI, 2006). O desafio, então, da atividade turística no século XXI, estará nas articulações organizacionais, nas políticas institucionais e, principalmente, nas estratégias de gestão priorizadas que, integradas nas decisões globais, devem buscar o desenvolvimento sustentável em todos os âmbitos de suas relações. Caberão, nesse sentido, medidas sanitárias que garantam a circulação e a segurança dos viajantes, pois a retomada do turismo diante da pandemia global imposta pelo Coronavírus ${ }^{4}$ desde o início dos anos de 2020 seguirá exigindo medidas cada vez mais cautelosas de ações da humanidade.

Tal como a sustentabilidade é priorizada no manejo dos agrossistemas (KAUFMANN; REINIGER; WIZNIEWSKY, 2018) no turismo, o uso sustentável está na utilização dos espaços com a responsabilidade de usufruir dos recursos existentes de forma equilibrada e inserida num processo de ativação capaz de possibilitar o desenvolvimento endógeno (BENI, 2006). À luz de novas possibilidades de aproveitamento das oportunidades promovidas pela globalização, a dimensão espacial local adquire o papel de protagonista de sua gestão, em que a reação ao global manifesta-se como uma estratégia de valorização cultural no território atual.

Nesse processo, as novas oportunidades em torno da relação entre o ser humano e o território buscam não somente legitimar a produção, a indústria e os serviços dos ambientes rurais e urbanos, mas também potencializar atividades capazes de agregar valor de forma sustentável. É o que se espera da atividade turística no momento de sua inserção num destino, seja pela capacidade de multiplicação e distribuição de renda, seja pela valorização da identidade local que estimula ou outros efeitos evidenciados no ambiente natural.

No âmbito internacional, alguns aspectos têm trabalhado contra a atividade turística sustentável, principalmente porque grandes componentes de transporte, das dinâmicas culturais, competições de recursos e o consumismo exagerado de riquezas fazem com que as ações não sejam tão eficientes. Cooper et al. (2007) aponta que os aspectos econômicos, ambientais, socioculturais e os limites de capacidade de cargas irreais tem atuado contra o turismo sustentável, seja em momentos de estímulo à inflação, de poluição do ar pelas companhias aéreas, seja de massificação de turistas em comunidades locais, que não se adaptam a nada e tratam de observar e incentivar a comercialização de produtos diferentes dos hábitos locais.

Por outro lado, além das dificuldades enfrentadas pelo uso do turismo sustentável de maneira útil e aceitável, existem novas abordagens que deverão diminuir algumas ameaças à viabilização da atividade, seja na ordem internacional, nacional ou local. Além de limites de capacidade de carga, uma mudança comportamental dos interessados no turismo, principalmente em ações e políticas públicas. poderia tornar os produtos disponíveis mais sustentáveis e punindo com

\footnotetext{
${ }^{4}$ No Brasil, o Ministério de Turismo (MTUR, 2020) lançou, em meados de abril, o Manual sobre Coronavírus, em parceria com o Centro de Operações de Emergências em Saúde Pública para o novo Coronavírus (COEnCoV) do Ministério da Saúde do Governo Federal, de modo a auxiliar as ações do setor, a manutenção do emprego, a garantia da liquidez das empresas e a revisão de impostos e regulamentos.
} 
mais eficiência as ações destruidoras de muitos residentes locais, turistas e das organizações que acarretam prejuízos e custos irreversíveis ao planeta.

No processo de desenvolvimento local, Pecqueur (2005), revela a possibilidade de novas estratégias de desenvolvimento, em seu sentido construído e atrelado à valorização de atividades locais, que permitem aos atores se reorganizarem nas novas economias emergentes, seja a solidária, criativa, da experiência, verde, etc. Para o autor, a flexibilidade dos sistemas territoriais atuais, aos quais os atores devem estar pertencentes ao processo, e não somente representados, possivelmente identificará novos e diferentes modos de organização produtiva capazes de se tornarem elementos de desenvolvimento local, como é o caso das atividades que acenarem para o uso do turismo.

Por esta lógica, a atividade turística como elemento de desenvolvimento local é um componente capaz de estimular estrategicamente o sistema produtivo local, reunindo em torno de uma demanda turística variáveis capazes de evidenciar melhoria de vida, bem-estar social, produzir o efeito multiplicador da renda, revitalizar e valorizar o patrimônio local, garantir liberdade de ação, melhorar a infraestrutura básica e turística.

Nesse aspecto, conforme Cooper et al. (2007), o turismo é um verdadeiro catalisador de desenvolvimento à medida que sua gestão for capaz de equilibrar os usos aos princípios sustentáveis da ação. O planejamento da atividade turística tem como perspectiva valorizar o sentido territorial, uma vez que se dispõe, em sua essência, a perspectivas sustentáveis, de âmbito comunitário, cujas horizontalidades atentam para a promoção de ações conjuntas e afinadas, com políticas e responsabilidades sobre os efeitos globais produzidos na sociedade.

\section{O SENTIDO DA AGROECOLOGIA NO ÂMBITO DO TURISMO}

As teorizações sobre o turismo na esfera transdisciplinar ainda estão em discussão, importando para o momento o entendimento de que o fenômeno turístico é um novo saber a ser compreendido enquanto área do saber na esfera atual, conforme afirma Rejowski (1996). Nesse âmbito, a questão da sustentabilidade vem sendo defendida pelas organizações internacionais, que apostam no setor turístico como alternativa sustentável de desenvolvimento. Isso se deve à capacidade de mudanças e atitudes que a atividade possui juntos às comunidades locais e mesmo nos setores de grandes impactos, como os transportes, a hospedagem, a alimentação, entretenimento e lazer, o agenciamento de viagens, o comércio e outros gastos turísticos decorrentes das viagens (CERETTA, 2005).

Corroborando com os objetivos do desenvolvimento sustentável - ODS, aprovados em 2015 por mais de 190 Estados - Membros da Organização das Nações Unidas (ONU), estes objetivos estão presentes nas esferas econômica, social e ambiental. São atividades que visam erradicar a pobreza de todas as formas e dimensões, além de estimular ações para a melhoria da vida das pessoas ao redor do mundo. As projeções da Agenda 2030 envolvem tarefas realizadas pelos governos nacionais e subnacionais, sociedade civil, organismos internacionais e organizações não-governamentais (PNUD, 2017).

O turismo sustentável surge entre os objetivos com a prerrogativa de que até 2030 é preciso que os Estados-membros elaborem e implementem políticas para promoção do turismo sustentável, gerador de renda, promotor da cultura e dos produtos locais. Além deste, os Estados-membros deverão desenvolver e implementar ferramentas para monitorar os impactos do desenvolvimento sustentável para que o turismo seja de fato sustentável (PNUD, 2017). 
A assertiva de que o turismo é um elemento global e um fenômeno comprometido com a construção social dos lugares mostra que a sua matéria-prima, recursos culturais e naturais são sobrelevados como parte dos elementos identitários e distintivos de um território, ao mesmo tempo em que servem de substrato para a sua valorização (PECQUEUR, 2005; SABOURIN, 2011). A valorização da atividade turística em âmbito global aparece como uma possibilidade de salvaguarda dos territórios, buscando na sustentabilidade a baliza para o uso racional e responsável.

Como aponta Beni (2006), a sustentabilidade que se propõe no turismo envolve a compreensão de uma série de dimensões e cenários, cujo alcance conjuntural possibilita o desenvolvimento racional da atividade de maneira a torná-la efetivamente sustentável. São estas dimensões que almejam a sustentabilidade social, ecológica, econômica, cultural e político-institucional, ao mesmo tempo em que envolvem pressupostos de alcance espacial, mercadológico, administrativo, organizacional, jurídico e financeiro. O desenvolvimento sustentável do turismo como um todo desencadeia um processo de reconstrução e reapropriação de um determinado território, a partir dos interesses coletivos dos atores sociais, e significativamente das responsabilidades geradas pelo uso de recursos naturais e culturais.

Nesta nova ordenação do turismo, será obedecida não mais a racionalidade da acumulação e do consumismo, mas principalmente a qualidade de vida do ser humano e da natureza, a permissão de novos desafios, de novas atitudes, da aceitação das diferenças, das artes, da crença e do respeito, em uma esfera que transcende a razão e a emoção a curto, médio ou longo prazos. Além disso, nesta lógica se contemplam as necessidades e expectativas coletivas da base local, com a participação ativa da sociedade civil, organizada de forma multi escalar, buscando adotar a alternativa que melhor viabilize sua inserção no processo de desenvolvimento sustentável. Desse modo, o desenvolvimento do turismo sob a perspectiva da sustentabilidade e das dimensões multi e transdisciplinares que o caracterizam, pode elevar as condições de vida das comunidades envolvidas, estimular e favorecer o crescimento de outras atividades no espaço sem fronteiras, interagir com todos os segmentos da sociedade, incorporar o planejamento estratégico ambientalmente justo, auxiliar na cobertura de gastos com preservação ambiental, intensificar a autoestima da comunidade local, incentivando seu engajamento no processo de desenvolvimento, monitorar, assessorar e administrar os impactos do turismo, desenvolvendo métodos confiáveis de gestão estratégica, bem como o uso produtivo de terras consideradas marginais (BENI, 2006).

No entanto, só um novo olhar do campo do turismo e da agroecologia pela sociedade permitirá que a sustentabilidade seja premissa para a sobrevivência no ecossistema. Kaufmann, Pasqualotto e Sena $(2019$, p. 8) expõem que, "nas últimas décadas, instituições oficiais de extensão rural, entidades da sociedade civil e a academia têm orientado grandes esforços para promover uma agricultura de base ecológica, tendo os pressupostos da Agroecologia como referência". Para Gliessman (2003), a base da agroecologia é o conceito de ecossistema, que se define como um sistema funcional de relações complementares entre organismos vivos e seu ambiente, delimitado por bordos definidos arbitrariamente, que no espaço e no tempo parecem manter um equilíbrio.

Nesta concepção, a agroecologia está contida em todas as áreas e deste todo se molda a sustentabilidade das ações do ser humano e as reações da natureza sobre as ações, não tendo sentido tratar de agroecologia somente no âmbito da agricultura, mas dela e de todas as áreas que dão forma à existência física ou imaginária. Assim, a agroecologia perpassa por todas as áreas, impacta-as 
e é impactada. O pensamento agroecológico é a teia que deve tecer todas as áreas do ecossistema, pois a poluição, a degradação, o envenenamento ou qualquer outro feito ambiental é responsabilidade da sociedade como um todo e é dela que se espera o start para a reparação.

Desse modo, o sentido da agroecologia no âmbito do turismo consiste em monitorar os elementos capazes de minimizar os efeitos globais que a atividade turística pode produzir, seja pelo deslocamento da demanda, seja pela necessidade de organização da oferta junto aos destinos turísticos. O cruzamento entre a prática de turismo e a agroecologia perpassa os mais diversos setores da atividade, desde o transporte, o setor de eventos, os meios de hospedagem e, singularmente, o setor de alimentação, pela sua produção artesanal e identitária preservada. Nos restaurantes onde a gastronomia típica é o símbolo da cultura local, a prática da agroecologia ajuda a movimentar os circuitos curtos, a produção orgânica, a propriedade familiar dos pequenos municípios e, singularmente, a valorização de pratos típicos e receitas de herança cultural que fazem do saber fazer, algo rememorado e singular. Além disso, a agroecologia também provoca midiaticamente a valorização da prática do turismo com base local, endógeno e com sentido territorial, de maneira que a comunidade local sinta-se sensibilizada e capacitada para receber e trabalhar o produto turismo como um dispositivo de valor de salvaguarda do patrimônio local. A falta de informações e a negligência sobre os reais efeitos do turismo nas comunidades têm acelerado a destruição de comunidades, o que mostra a necessidade de planejamento da atividade antes de sua divulgação e comercialização.

Outro fator é o uso racional dos recursos naturais e culturais por parte das empresas ligadas direta e indiretamente ao turismo, de modo que seja formada uma rede de relações e usos que assumam pari passu as responsabilidades de usos e danos causados em decorrência do fluxo de turistas.

\section{DISCUSSÕES DA APROXIMAÇÃO DA AGROECOLOGIA E O TURISMO: A RESPONSABILIDADE AMPLIADA}

Considerar a Agroecologia e o Turismo como dois saberes transdisciplinares, que se identificam quando 0 assunto é a busca da sustentabilidade, significa entender que tanto uma quanto a outra disciplina fazem parte de um conjunto de áreas que superam o conhecimento estático dos números e das provas de verdades, uma vez que é mais importante reconhecer as ações e reações decorrentes das atitudes de tais áreas no ecossistema.

O entendimento transdisciplinar permite ir além de visões simplistas, economicistas ou mesmo tecnicistas ou outras encontradas nos termos reducionistas que tanto o turismo como a agroecologia possam ter sido posicionadas. Tratar o turismo pelo viés da transdisciplinaridade amplia 0 entendimento da nova realidade em que o movimento turístico se efetua; da mesma forma que a agroecologia, pois a transdisciplinaridade é complementar à aproximação disciplinar. Isto faz emergir, da confrontação das disciplinas, dados novos que as articulam entre si, oferecendo uma visão da natureza e da realidade, como mostra a Carta da Transdisciplinaridade (1994).

Esta perspectiva entrelaça os campos dos saberes debatidos, os quais são compostos por múltiplos aspectos. Neste sentido, o desenvolvimento sustentável se fortalece, visto que pensar novas ideias para a sustentabilidade implica em considerar as áreas que se correspondam. Neste caso, ambas buscam ações sustentáveis para a manutenção do planeta, bem como das próprias atividades em que estão inseridas, pois a existência da atividade turística, bem como as 
perspectivas do saber agroecológico para a sobrevivência do planeta, amplia-se com atitudes responsáveis, de valorização da riqueza e, singularmente, pela preservação do patrimônio da terra, natural e cultural.

As reflexões e saberes transdisciplinares para 0 desenvolvimento sustentável a partir da Agroecologia e Turismo revelam que o pensamento agroecológico, ao tecer as mais diversas áreas do ecossistema, carrega consigo a sinalização para que as demais áreas se apropriem e usufruam de seus preceitos que, no caso da atividade turística, atinge diversos sistemas e subsistemas. Buscar condições de desenvolvimento do turismo nos territórios significa considerar a presença de diferentes áreas, tais sejam os eventos, os meios de hospedagem, os transportes, o setor de alimentação, entre tantas outras, as quais necessitam de balizas para seus efeitos.

Se a agroecologia pode tecer os fios de uma teia de responsabilidade nas diversas áreas em que retroalimenta, a sua transdisciplinaridade pode cercar o turismo para que suas atividades possam ser capazes de minimizar os impactos sociais, econômicos e ambientais produzidos, quando o mau uso é evidenciado. Por vezes, tais impactos negativos atingem esferas multidimensionais, na mesma proporção do efeito multiplicador de renda que o turismo alcança (LEMOS, 2001).

Ou seja, sempre que o saber transdisciplinar da agroecologia se somar à perspectiva de desenvolvimento sustentável do turismo, será possível que os efeitos diretos, indiretos e induzidos dos impactos produzidos possam atingir a esfera subjetiva da compreensão de que as responsabilidades pela sobrevivência do planeta também condizem com a qualidade de vida que o próprio ser humano elegeu. A ampliação das responsabilidades deve ser a baliza para o real sentido do desenvolvimento, de modo que a aproximação da agroecologia e o turismo esteja condicionada a tal propósito, sob pena de sucumbir seus princípios e alienar sua eficiência aos interesses de uma ou outra área.

Aos poucos, o fator economicista da atividade cede discretamente espaço para o fator social e a premissa mundial evidencia que nem todo o espaço poderá ser explorado turisticamente, numa medida preservacionista e sustentável do turismo e dos locais eleitos para sua implantação. Para Lemos (2001), a contribuição mundial do turismo deverá estar vinculada significativamente na valorização de riquezas e na melhora do bem-estar social dos cidadãos, refletidos na geração de emprego, na distribuição e circulação da renda, na transferência de recursos entre regiões, nos investimentos e inovações que promove, no desenvolvimento de infraestruturas coletivas que estimula, na conservação do ambiente e na recuperação do patrimônio, nas oportunidades de desenvolvimento territorial e, principalmente, na responsabilidade de uso do ecossistema. O turismo, assim, propicia maior visibilidade ao ambiente natural e, por consequência, maior atenção às práticas agroecológicas e ao zelo com o lugar visitado. De igual forma, a agroecologia instiga a planejar um turismo menos massivo, menos poluidor e agressivo às comunidades, já que é a atividade turística que terá que se adequar aos processos agroecológicos e não ao contrário.

Nessa perspectiva, o turismo seguirá articulado como uma nova e promissora alternativa de renda, de trabalho, de emprego, de valorização cultural, de diversificação produtiva e de forte presença no movimento global, capaz de valorizar e contribuir sócio e economicamente para o desenvolvimento sustentável dos territórios. 


\section{CONSIDERAÇÕES FINAIS}

A complexidade das áreas da agroecologia e do turismo revelaram ao longo do estudo que a sustentabilidade é um dos principais caminhos para atingir os propósitos de salvaguarda dos ecossistemas. Quando a transdisciplinaridade é aceita por estas duas áreas do saber, compreender-se-á o real sentido das ações e tarefas de valor ecológico nos mais diversos locais e destinos de força e atratividade turística.

A construção de atitudes responsáveis em torno do ecossistema envolve o saber e o fazer de atores, instituições, poderes e da própria comunidade em prol de um melhor e equilibrado uso dos recursos naturais e culturais existentes na realidade. A salvaguarda do patrimônio é um convite para que o desenvolvimento do turismo seja a principal alternativa, de identificar de diferentes ações e minimizar os impactos causados pelo mau uso da atividade turística. O sentido do desenvolvimento sustentável do turismo está contido e condicionado ao usufruto da perspectiva transdisciplinar da agroecologia, de modo que as ações do sistema de turismo também possam ser alimentadas e retroalimentadas pelas premissas da responsabilidade compartilhada.

Portanto, o desenvolvimento do turismo sustentável alicerçado na dimensão transdisciplinar necessita do rigor das políticas de salvaguarda do patrimônio e a aceitação de que o inesperado e o imprevisível podem surgir a todo o momento. Tem-se a certeza de que tanto a agroecologia como o turismo são saberes que, se tratados com equilíbrio, nas suas esferas de ações e interesses, permitem superar qualquer iniciativa que agrida os princípios da sustentabilidade, embora se possa ser tolerante sobre os diferentes pontos de vistas que as áreas possuem. Há que reconhecer que tais elementos possam flexibilizar suas ações, em prol do equilíbrio do saber e da sobrevivência da humanidade, tão testemunhadas ultimamente.

\section{REFERÊNCIAS}

PLATAFORMA AGENDA 2030. Objetivos do Desenvolvimento Sustentável. Disponível em: http://www.agenda2030.com.br/. Acesso em: 03 dez. 2020.

BENI, M. C. Análise estrutural do turismo. São Paulo: Senac, 2003.

BENI, M. C. Política e planejamento de turismo no Brasil. São Paulo: Aleph, 2006.

BRANDENBURG, A. Movimento agroecológico: trajetórias, contradições e perspectivas. Revista Desenvolvimento e Meio Ambiente, Curitiba, n. 6. p. 11-28, jul./dez. Disponível em: https://revistas.ufpr.br/made/article/view/22125/14489. Acesso em: 05 dez. 2020.

BRASIL. Ministério do Turismo. Manual sobre coronavirus. 2. ed. Brasília, DF: Ministério do Turismo, 2020.2 Disponível em: http://www.turismo.gov.br/images/manuais/Manual\%20Coronav\%C3\%ADrus\%20\%2001_05.pdf. Acesso em: 31 jul. 2019.

BRASIL. Ministério do Turismo. Ano de 2018 fecha com aumento no gasto de estrangeiros no Brasil, 2019. Disponível em: http://www.turismo.gov.br/\%C3\%BAltimas-not\%C3\%ADcias/12333-ano-de-2018- 
fecha-com-aumento-nos-gastos-de-estrangeiros-no-brasil.html. Acesso em: 31 jul. 2019.

CAPORAL, F. R. Agroecologia: uma nova ciência para apoiar a transição a agriculturas mais sustentáveis. Brasília: MDA/SAF, 2009.

CARTA DA TRANDISCIPLINARIDADE. Manifesto da Transdisciplinaridade. I Congresso Mundial de Transdisciplinaridade - Convento da Arrábida, 6 de novembro de 1994. Basarab Nicolescu - São Paulo: TRIOM, 1999.

CENTRO DE ESTUDOS TRANSDISCIPLINARES (CETRANS). 0 que é a TransD? São Paulo: USP, 2019. Disponível em: http://cetrans.com.br/cetrans/o-que-e-atransd/. Acesso em: 12 fev. 2019.

CERETTA, C. A composição do gasto turístico nos Municípios de Canela e Gramado - Rio Grande do Sul/RS. Caxias do Sul: Universidade de Caxias do Sul, 2005.

COSTA GOMES, J. C.; BORBA, M. Limites e possibilidades da Agroecologia como base para sociedades sustentáveis. Revista Ciência \& Ambiente, Santa Maria, n. 29, 2004.

COOPER, C.; FLETCHER, J.; FYALL, A. et al. Turismo: princípio e prática. Trad. Alexandre Salvaterra. 3. ed. Porto Alegre: Bookmann, 2007.

DEL PUERTO, C. B. O cemitério como patrimônio e atrativo turístico considerando a trama morte e vida nas necrópoles. 2016. 156 f. Dissertação (Mestrado em Turismos) - Universidade de Caxias do Sul, Caxias do Sul, 2016.

GLIESSMAN, S. R. Agroecología y agroecosistemas. Ciência \& Ambiente, v. 27, p. 107-120, 2003.

GUZMÁN, S. A perspectiva sociológica em Agroecologia: uma sistematização de seus métodos e técnicas. Agroecologia e Desenvolvimento Rural Sustentável, v. 3 , n. 1, p. 18-28, 2002.

KAUFMANN, M. P.; PASQUALOTTO, N.; SENA, M. M. A construção do conhecimento agroecológico no território central do Rio Grande do Sul: uma experiência baseada na metodologia campesino a campesino. Extensão Rural, Santa Maria, v. 26, n. 3, p. 7-16, jul./set. 2019. Disponível em: https://periodicos.ufsm.br/extensaorural/article/view/39859/pdf. Acesso em: 09 jul. 2020.

KAUFMANN, M. P.; REINIGER, L. R. S.; WIZNIEWSKY, J. G. A conservação integrada da agrobiodiversidade crioula. Revista Brasileira de Agroecologia, v. 13, n. 2 , p. 36-43, 2018. Disponível em: http://revistas.abaagroecologia.org.br/index.php/rbagroecologia/article/view/17397. Acesso em: 09 jul. 2020.

LEMOS, L. de. Turismo: que negócio é esse? São Paulo: Papirus, 2001. 
LONGARAY; A. A. BEUREN, I. M. Caracterização da pesquisa em contabilidade. In: BEUREN, I. (Org). Como elaborar trabalhos monográficos em contabilidade: teoria e prática. São Paulo: Atlas, 2003. p. 21-43,

MOESCH, M. M. A produção do saber turístico. 2. ed. São Paulo: Contexto, 2002.

ORGANIZAÇÃO MUNDIAL DO TURISMO (OMT). Os ingressos por turismo internacional cresceram em 4\% em 2012. Madrid, 2013. Disponível em: http://media.unwto.org/es/press-release/2013-05-15/los-ingresos-por-turismointernacional-crecieron-un-4-en-2012 Acesso em: 04 jun. 2013.

PAIVA, R. L. Pensamento complexo, agroecologia e agrotóxicos: análise da interrelação entre ciência, movimentos sociais e mídia no processo de construção social das informações sobre toxidade e risco. Estudos Sociedade e Agricultura, v. 27, n. 3, p. 547-565, 2019.

PECQUEUR, B. O desenvolvimento territorial: uma nova abordagem dos processos de desenvolvimento para as economias do Sul. Raízes, v. 24, n 01 e 02, p.10-22, 2005.

PREISS, P. V. As dimensões do conhecimento agroecológico: a experiência dos agricultores familiares assentados em Viamão, RS. Redes, v. 25, n. 1, p. 104-134, 2020. Disponível em: https://online.unisc.br/seer/index.php/redes/article/view/14685. Acesso em: 12 jun. 2020.

PROGRAMA DAS NAÇÕES UNIDAS PARA O DESENVOLVIMENTO (PNUD). Acompanhando a agenda 2030 para o desenvolvimento sustentável. Brasília, 2017.

REJOWSKI, M. Turismo e pesquisa científica. São Paulo: Papirus, 1996.

RICHARDSON, R. J. Pesquisa social: métodos e técnicas. São Paulo, Atlas, 1999.

SABOURIN, E. Teoria a reciprocidade e sócio-antropologia do desenvolvimento. Sociologias, v. 13, n. 27, p. 24-51, 2011.

SILVA, M. A. C.; SCHINAIDER, A. D.; DORNESL, F. M. et al. O turismo rural e os produtos locais: construção social da qualidade a partir da teoria das convenções. Revista Rosa dos Ventos, v. 9, n. 3, 2017. Disponível em: http://www.ucs.br/etc/revistas/index.php/rosadosventos/article/view/4749/pdf. Acesso em: 07 jul. 2020.

SONAGLIO, K. E.; LAPOLLI, E. M. Uma abordagem transdisciplinar para o desenvolvimento sustentável do ecoturismo. Turismo - Visão e Ação, v. 5, n. 2, p. 163, 2003.

TORRESAN, V. O crescimento do mercado do turismo no Brasil e as projeções para 2019. Latin America Business Stories, 2018. Disponível em: https://labs.ebanx.com/pt-br/turismo/o-crescimento-do-mercado-do-turismo-no-brasile-as-projecoes-para-2019. Acesso em: 31 jul. 2019. 
WORLD WIDE FUND FOR NATURE (WWF) - Organização de Conservação Global. O que é desenvolvimento sustentável? 2014. Disponível em: http://www.wwf.org.br/natureza_brasileira/questoes_ambientais/desenvolvimento_su stentavel/. Acesso em: 13 fev. 2014. 